\title{
The "smoker's paradox" in patients with acute coronary syndrome: a systematic review
}

\author{
Erlend Aune ${ }^{1 *}$, Jo Røislien ${ }^{2,3}$, Mariann Mathisen ${ }^{4}$, Dag S Thelle ${ }^{2}$ and Jan Erik Otterstad ${ }^{1}$
}

\begin{abstract}
Background: Smokers have been shown to have lower mortality after acute coronary syndrome than nonsmokers. This has been attributed to the younger age, lower co-morbidity, more aggressive treatment and lower risk profile of the smoker. Some studies, however, have used multivariate analyses to show a residual survival benefit for smokers; that is, the "smoker's paradox". The aim of this study was, therefore, to perform a systematic review of the literature and evidence surrounding the existence of the "smoker's paradox".
\end{abstract}

Methods: Relevant studies published by September 2010 were identified through literature searches using EMBASE (from 1980), MEDLINE (from 1963) and the Cochrane Central Register of Controlled Trials, with a combination of text words and subject headings used. English-language original articles were included if they presented data on hospitalised patients with defined acute coronary syndrome, reported at least in-hospital mortality, had a clear definition of smoking status (including ex-smokers), presented crude and adjusted mortality data with effect estimates, and had a study sample of $>100$ smokers and > 100 non-smokers. Two investigators independently reviewed all titles and abstracts in order to identify potentially relevant articles, with any discrepancies resolved by repeated review and discussion.

Results: A total of 978 citations were identified, with 18 citations from 17 studies included thereafter. Six studies (one observational study, three registries and two randomised controlled trials on thrombolytic treatment) observed a "smoker's paradox". Between the 1980s and 1990s these studies enrolled patients with acute myocardial infarction (AMI) according to criteria similar to the World Health Organisation criteria from 1979. Among the remaining 11 studies not supporting the existence of the paradox, five studies represented patients undergoing contemporary management.

Conclusion: The "smoker's paradox" was observed in some studies of AMl patients in the pre-thrombolytic and thrombolytic era, whereas no studies of a contemporary population with acute coronary syndrome have found evidence for such a paradox.

\section{Background}

The term "smoker's paradox" was introduced into scientific discourse more than 25 years ago following observations that smokers (in comparison to non-smokers) experience decreased mortality following an acute myocardial infarction (AMI) [1-4]. Braunwald's recent textbook on heart disease argues that the observation that smoking predicts better outcome following various reperfusion strategies is not because of any benefit from smoking but simply because smokers are likely to

\footnotetext{
* Correspondence: erlend.aune@siv.no

'Department of Cardiology, Vestfold Hospital Trust, Tønsberg, Norway

Full list of author information is available at the end of the article
}

undergo such procedures at a much younger age and hence have on average lower comorbidity [5].

In a recent study we observed a $41 \%$ reduction in oneyear mortality in unselected AMI patients following the switch from a conservative approach in 2003 to the introduction of routine early invasive management in 2006 [6]. In a sub-analysis of patients with non-ST-segment elevation myocardial infarction (NSTEMI) this treatment effect was especially pronounced for smokers. Current smoking was an independent predictor for oneyear mortality in the 2003 cohort, but not in the 2006 cohort [7]. These observations motivated us to perform a systematic review of the literature (observational studies and randomised trials) surrounding the "smoker's

\section{Biomed Central}


paradox" in order to explore possible differences between study populations with or without this phenomenon.

\section{Methods}

Literature search and study selection

We searched three electronic databases: EMBASE (from 1980 onward), MEDLINE (from 1963 onward) and the Cochrane Register of Controlled Trials. Our search strategy combined text words and subject headings identifying reports relating to acute coronary syndrome/ AMI, smoking status and mortality. The search included literature published by 22 September 2010. Due to the long time spans of the databases we decided to perform two slightly different searches in MEDLINE and EMBASE, one from $1963 / 1980$ to 1995 , the other from 1996 to date of search. (See Additional file 1 for the full search strategy.) The reference lists of identified studies were also scanned to identify any other relevant studies, with the search strategy expanding accordingly.

The original observations of the "smoker's paradox" was made in patients with an AMI diagnosed according to the World Health Organisation (WHO) criteria from 1979 [8]. With the introduction for new diagnostic criteria of AMI in 2000 [9] and 2007 [10] in mind, we chose to extend the search to include patients with STsegment elevation myocardial infarction (STEMI) and non-ST-segment elevation acute coronary syndrome (NSTEMI and unstable angina pectoris [UAP]).

Two investigators (EA and JEO) independently reviewed all titles and abstracts to identify potentially relevant articles and resolved discrepancies by repeated review and discussion. If two or more studies presented the same data from a single patient population, we included these data only once in the review.

No review protocol was used, but we prospectively defined the following criteria for the inclusion of studies into our review:

- Studies of patients hospitalised for acute coronary syndrome (ACS), including the previous WHO criteria for AMI [8] and the more recent definition of ACS, including STEMI, NSTEMI and UAP [9].

- The publication should provide a clear definition of smoking status into current, former and neversmokers, including baseline characteristics of each group with age as a minimum. In case former smokers were not defined separately, a minimum requisite was that they had to be defined and characterised either as smokers, non-smokers or per definition were excluded from the analysis.

- Both crude and adjusted total mortality rates should be presented. Effect estimates should be provided, and "age" was a minimum requirement as a covariate.
- The length of follow-up should be reported and include at least hospital mortality. Studies reporting only post-discharge mortality were excluded.

- Only English-language original articles were included.

- The study should include $>100$ smokers and $>100$ non-smokers.

Our own study exploring one-year mortality among smokers vs. non-smokers with NSTEMI was published after the literature search was finalised, but the results were known to us by September 2010, and the study has therefore been included in this review [7].

\section{Results}

The study selection process is presented in Figure 1. In total, 978 unique citations were identified. Based upon titles and abstracts, 903 citations could be excluded. Accordingly, 75 full-length original articles were considered in depth for inclusion, with 18 publications from 17 studies (7 randomised trials and 10 observational studies/registries) meeting all inclusion criteria [7,11-27]. The Superior Yield of the New strategy of Enoxaparin, Revascularization and GlYcoprotein IIb/IIIa inhibitors (SYNERGY) trial is presented by two publications, one demonstrating crude mortality rates [22] and another adjusted mortality rates [24]. The studies were published between 1991 and 2009 and enrolled patients from 1982 through till 2007. Five studies [7,14,16,19,22,24] were considered to represent a contemporary population of ACS and mainly included patients according to the diagnostic criteria from 2000 [9]. The other studies were based upon patients included according to the WHO criteria [8] in the 1980s and 1990s.

The follow-up time in the 17 included studies varied from in-hospital to three years. Out of six studies with in-hospital follow-up, two registries demonstrated a "smoker's paradox". Four out of six studies with followup between one month and six months found evidence for the paradox, whereas none of the five studies that followed patients for one year or more did so.

\section{Study categories and adjusted mortality rates}

Study characteristics, with crude and adjusted mortality rates expressed as odds ratios and hazard ratios and relative risks with 95\% confidence intervals according to smoking status, are presented in Table 1 . The studies have been sub-divided into six categories according to study design. The effect estimates for adjusted mortality rates are presented in Figure 2.

\section{Randomised controlled trials (RCT) in patients treated with fibrinolysis for STEMI}

Both the International Tissue Plasminogen Activator/ Streptokinase Mortality Trial [12] and the Global 


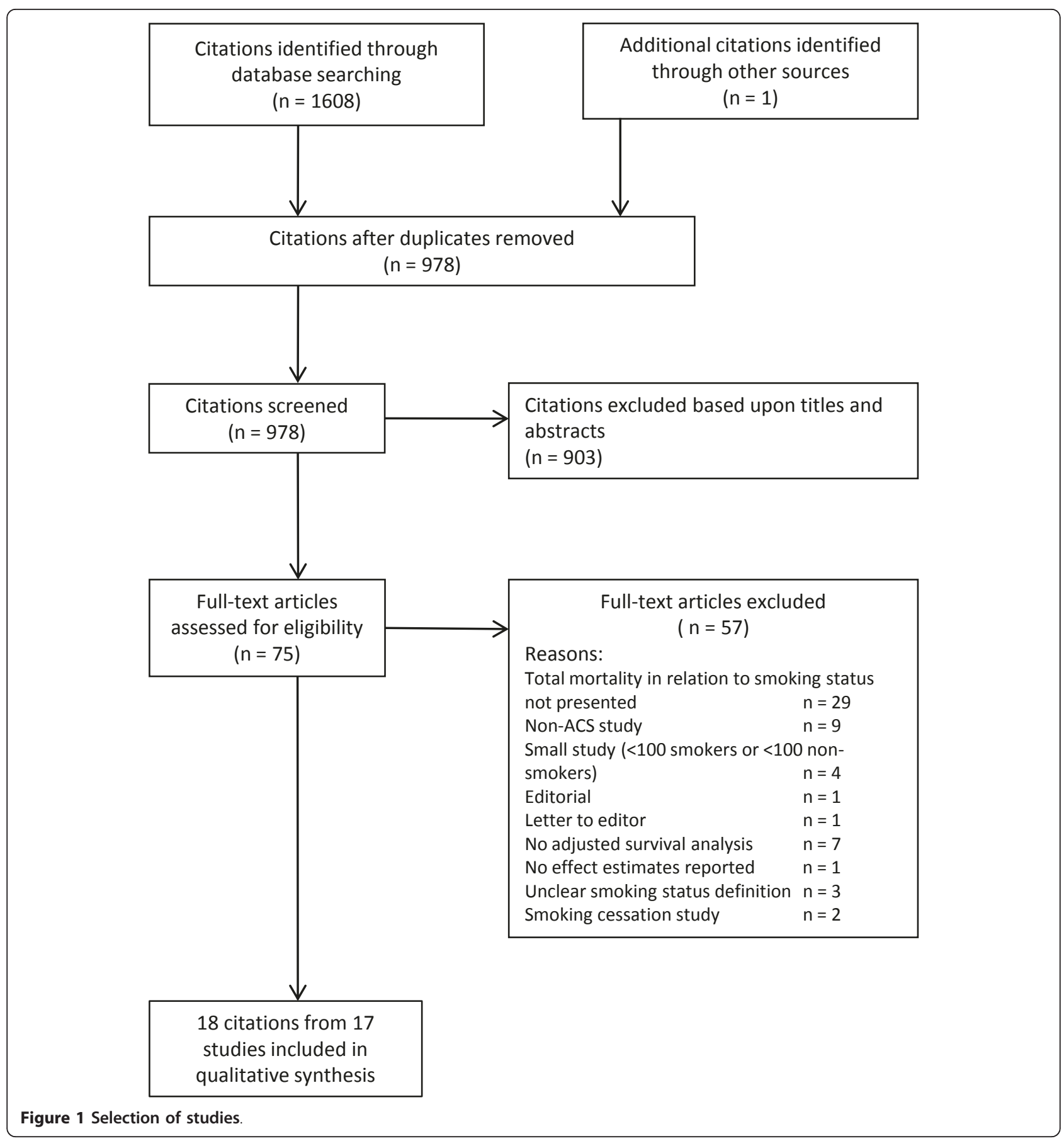

Utilization of Streptokinase and Tissue-Plasminogen Activator for Occluded Coronary Arteries (GUSTO-I) trial [13] demonstrated higher adjusted mortality rates among non-smokers, that is, supporting a smoker's paradox. For the latter study, no such effect was observed in the angiographic substudy of 2,437 patients. The Gruppo Italiano per lo Studio della Sopravvivenza nell'Infarcto Micardico (GISSI-2) trial [23] included patients with the same factorial study design as the international study [12], but did not demonstrate any reduced adjusted in-hospital mortality for smokers compared with never-smokers.

RCT in STEMI treated with percutaneous coronary intervention (PCI)

In the Controlled Abciximab and Device Investigation to Lower Late Angioplasty Complications (CADILLAC) trial 2,082 patients with STEMI undergoing primary PCI were randomised to either angioplasty or stenting with 
Table 1 Study characteristics and mortality rates according to smoking status at index event

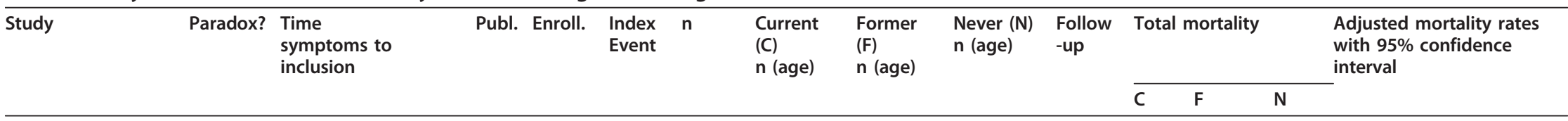

Randomised clinical trials in STEMI patients (thrombolytic treatment)

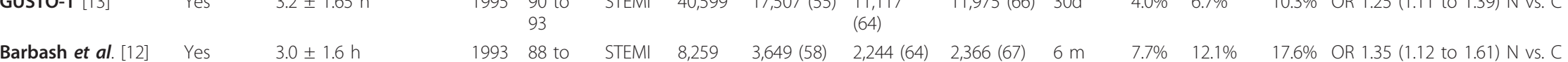

Barbash et al. [12] Yes $3.0 \pm 1.6 \mathrm{~h}$

GISSI-2 [23] No $\quad<3$ h in $70 \%$

$\begin{array}{llllllllllllll}1993 & 88 \text { to } & \text { STEMl } & 8,259 & 3,649(58) & 2,244(64) & 2,366(67) & 6 m & 7.7 \% & 12.1 \% & 17.6 \% & \text { OR } 1.35(1.12 \text { to } 1.61) \mathrm{N} \text { vs. C } \\ & 89\end{array}$

Randomised clinical trials in STEMI patients (invasive treatment)

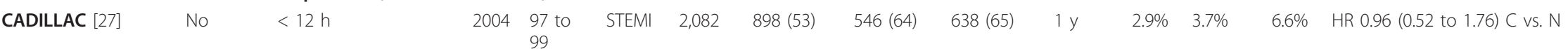

Randomised clinical trials in patients with NSTE-ACS (invasive treatment)

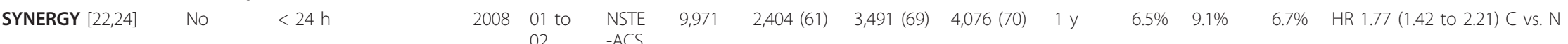

Multi-centre post-AMI randomised trials

TRACE [21] No 2 to $6 \mathrm{~d}$

OPTIMAAL [20] No $\quad<10 d$

\begin{tabular}{|c|c|c|c|c|c|c|c|c|c|c|c|}
\hline 1999 & $\begin{array}{l}90 \text { to } \\
92\end{array}$ & AMI & 6,485 & $3,341(64)$ & $1,420(71)$ & $1,724(74)$ & $3 y$ & $\begin{array}{l}26 \text { to } \\
27 \%\end{array}$ & $\begin{array}{l}38 \text { to } \\
39 \%\end{array}$ & $\begin{array}{l}42 \text { to } \\
43 \%\end{array}$ & HR 1.04 (0.93 to 1.15 ) C vs. N \\
\hline 2004 & $\begin{array}{l}98 \text { to } \\
99\end{array}$ & AMI & 5,475 & 1,832 (62) & $1,867(69)$ & 1,776 (71) & $2.7 \mathrm{y}$ & $16.3 \%$ & $\begin{array}{l}\text { Incl. in } \\
\text { C }\end{array}$ & $19.3 \%$ & $\begin{array}{l}\text { HR } 1.08 \text { (0.93 to } 1.25 \text { ) C+F vs. } \\
N\end{array}$ \\
\hline
\end{tabular}

Single-centre observational studies of patients with AMI

\begin{tabular}{|c|c|c|c|c|c|c|c|c|c|c|c|c|c|c|}
\hline Mølstad [25] & Yes & NA & 1991 & $\begin{array}{l}82 \text { to } \\
84\end{array}$ & AMI & 484 & $184(61)$ & Incl. in N & 456 (70) & $3 \mathrm{~m}$ & $\begin{array}{l}11 \text { to } \\
13 \%\end{array}$ & $\begin{array}{l}\text { Incl. in } \\
\mathrm{N}\end{array}$ & $\begin{array}{l}32 \text { to } \\
34 \%\end{array}$ & $\begin{array}{l}\text { HR } 0.62(0.36 \text { to } 1.04) \text { C vs. N } \\
+ \text { F } \\
\text { HR } 0.55 \text { (0.33 to } 0.93) \text { C vs. N } \\
+F\end{array}$ \\
\hline $\begin{array}{l}\text { Bettencourt et al. } \\
{[14]}\end{array}$ & No & NA & 2004 & $\begin{array}{l}01 \text { to } \\
02\end{array}$ & ACS & 901 & 369 (58) & Incl. in C & $532(69)$ & In-hosp. & $2.6 \%$ & $\begin{array}{l}\text { Incl. in } \\
\mathrm{F}\end{array}$ & $6.6 \%$ & $\begin{array}{l}\text { OR } 0.96 \text { (0.38 to 2.41) C+F vs. } \\
N\end{array}$ \\
\hline Gaspar et al. [16] & No & NA & 2009 & $\begin{array}{l}04 \text { to } \\
07\end{array}$ & ACS & 1,228 & $450(58)$ & Incl. in C & $778(68)$ & $6 \mathrm{~m}$ & $9.3 \%$ & $\begin{array}{l}\text { Incl. in } \\
\text { C }\end{array}$ & $13.1 \%$ & $\begin{array}{l}\text { OR } 1.25 \text { (0.61 to } 2.54) \mathrm{C}+\mathrm{F} \text { vs. } \\
\mathrm{N}\end{array}$ \\
\hline Aune et al..$^{\S}[7]$ & No & NA & 2010 & $\begin{array}{l}03 \text { to } \\
07\end{array}$ & NSTEMI & 381 & $103(63)$ & Incl. in N & $278(80)$ & $1 y$ & $22 \%$ & $\begin{array}{l}\text { Incl. in } \\
\mathrm{N}\end{array}$ & $27 \%$ & $\begin{array}{l}\text { HR } 2.61 \text { (1.43 to } 4.79) \text { C vs. N } \\
+\mathrm{F}\end{array}$ \\
\hline \multicolumn{15}{|l|}{ Registries } \\
\hline Gottlieb et al. [17] & No & NA & 1996 & 94 & $\mathrm{AMI}$ & 999 & $367(57)$ & Incl. in N & $632(67)$ & $6 \mathrm{~m}$ & $7.9 \%$ & $\begin{array}{l}\text { Incl. in } \\
\mathrm{N}\end{array}$ & $21.5 \%$ & $\begin{array}{l}\text { HR } 0.84 \text { (0.54 to 1.30) C vs. N } \\
+\mathrm{F}\end{array}$ \\
\hline $\begin{array}{l}\text { Andrikopoulos et } \\
\text { al. } \\
\text { [11] }\end{array}$ & No & $<24 \mathrm{~h}$ & 2001 & $\begin{array}{l}93 \text { to } \\
94\end{array}$ & AMI & 5507 & $3,853(59)$ & Excluded & $1,654(70)$ & In-hosp. & $7.4 \%$ & NA & $14.5 \%$ & RR 1.12 (0.86 to 1.44$)$ C vs. N \\
\hline NRMI 2 [18] & Yes & NA & 2002 & $\begin{array}{l}94 \text { to } \\
97\end{array}$ & AMl & 297,458 & $72,585(58)$ & Incl. in N & $\begin{array}{l}224,871 \\
(72)\end{array}$ & In-hosp. & $8.0 \%$ & $\begin{array}{l}\text { Incl. in } \\
\mathrm{N}\end{array}$ & $16.4 \%$ & $\begin{array}{l}\text { OR } 0.86 \text { (0.83 to } 0.90) \text { C vs. N } \\
+\mathrm{F}\end{array}$ \\
\hline ARIAM [26] & Yes & $\begin{array}{l}<24 \mathrm{~h} \\
\text { criterion }\end{array}$ & 2004 & $\begin{array}{l}95 \text { to } \\
01\end{array}$ & AMI & 17,761 & 5,796 (57) & $3,494(67)$ & $8,471(70)$ & $\begin{array}{l}\text { ICU/ } \\
\text { CCU }\end{array}$ & $5.0 \%$ & $9.3 \%$ & $13.3 \%$ & OR 0.77 (0.66 to 0.91$)$ C vs. N \\
\hline
\end{tabular}


Table 1 Study characteristics and mortality rates according to smoking status at index event (Continued)

\begin{tabular}{|c|c|c|c|c|c|c|c|c|c|c|c|c|c|c|}
\hline & & & & & UAP & 7,795 & 1,721 & 1,950 & 4,124 & $\begin{array}{l}\text { ICU/ } \\
\text { CCU }\end{array}$ & $0.7 \%$ & $1.0 \%$ & $1.5 \%$ & OR 0.81 (0.48 to 1.36 ) C vs. N \\
\hline IBERICA [15] & Yes & $<12 \mathrm{~h}$ in $82 \%$ & 2007 & $\begin{array}{l}97 \text { to } \\
98\end{array}$ & AMl & 7,796 & $3,057(56)$ & 1,730 & $2,839(65)$ & $28 d$ & $8.9 \%$ & $16.9 \%$ & $20.1 \%$ & OR 0.57 (0.42 to 0.78$)$ C vs. N \\
\hline GRACE [19] & No & NA & 2005 & $\begin{array}{l}99 \text { to } \\
02\end{array}$ & ACS & 19,325 & $5,276(57)$ & $5,691(67)$ & $8,358(71)$ & In-hosp. & $3.3 \%$ & $4.5 \%$ & $6.9 \%$ & OR 1.01 (0.80 to 1.27 ) C vs. N \\
\hline
\end{tabular}

ACS, acute coronary syndrome; AMI, acute myocardial infarction; CCU, coronary care unit; HR, hazard ratio; ICU, intensive care unit; OR, odds ratio; NA, not available; NST-ACS, non-ST-segment acute coronary syndrome; NSTEMI, non-ST-segment elevation myocardial infarction; RR, relative risk; STEMI, ST-segment elevation myocardial infarction; UAP, unstable angina pectoris. ${ }^{5}$ The adjusted HR is for the conservative syndrome; NSTEMI, non-ST-segment elevation myocardial infarction; RR, relative risk; STEMI, ST-segment elevation myocardial infarction; UAP, unstable
treatment cohort (2003) only. For the invasive cohort (2006) there was no difference in mortality for smokers and non-smokers (data not published). 


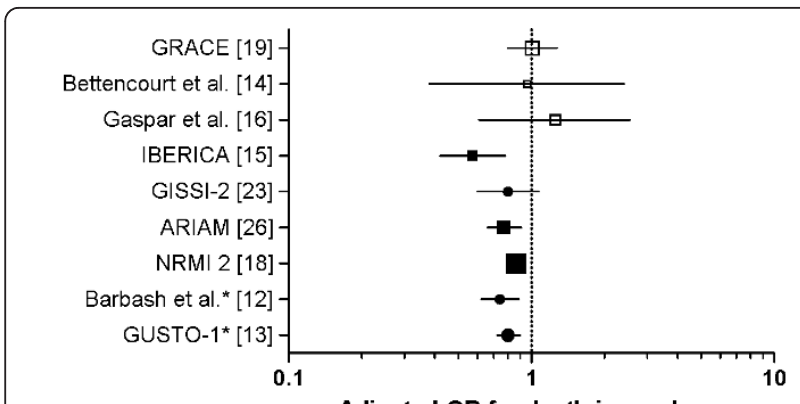

Adjusted OR for death in smokers

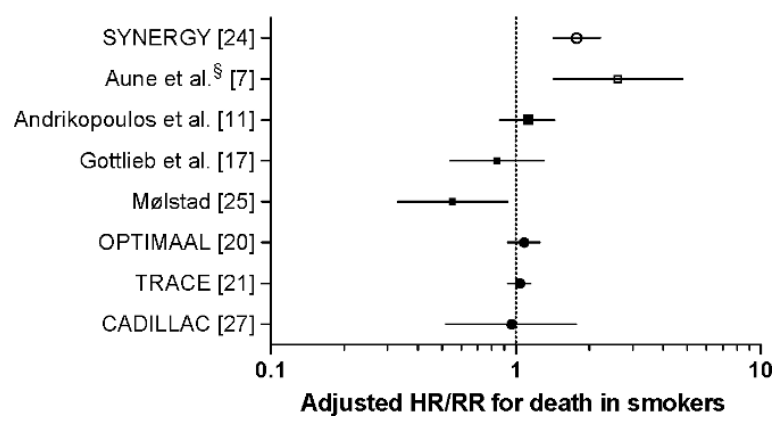

Figure 2 Forest plots of adjusted mortality in smokers vs. nonsmokers. Odds ratios (OR)/hazard ratios (HR) with 95\% confidence intervals for death during follow-up for smokers compared with non-smokers in the studies included. Circles indicate data derived from randomised trials. Squares indicate data derived from observational studies or registries. Open symbols indicate contemporary studies enrolling patients mainly after 2000. Closed symbols indicate older studies enrolling patients in the prethrombolytic and thrombolytic era. Symbol size reflects the sample size of the studies and registries. *Inverted OR from original paper. ${ }^{\S}$ The adjusted HR is for the conservative treatment cohort (2003) only. For the invasive cohort (2006) there was no difference in mortality for smokers and non-smokers (data not published).

or without abciximab [27]. Although current smokers had a lower crude mortality rate, the adjusted analysis did not find a lower mortality than that of non-smokers. RCT of non-ST-segment elevation acute coronary syndrome (NSTE-ACS) subjected to invasive management

In the SYNERGY trial [28] patients with NSTE-ACS were randomised to enoxaparin or unfractionated heparin and then underwent coronary angiography and subsequent PCI or coronary artery bypass grafting (CABG). The crude mortality rate after one year was similar among smokers and non-smokers [24]. In the adjusted analysis there was a significant mortality excess among smokers vs. non-smokers, supporting the unfavourable effect of current smoking at baseline [22].

\section{Multi-centre post-AMI studies from RCTs}

The TRAndolapril Cardiac Evaluation (TRACE) study consisted of 2,606 patients and aimed to determine whether patients with left ventricular dysfunction post AMI would benefit from long-term treatment with trandolapril vs. placebo [29]. In a study of 6,676 consecutive AMI patients screened for participation in the TRACE study, the long-term mortality was far lower among smokers than either ex- or non-smokers. In spite of this, the adjusted analysis did not give any evidence to support the existence of a smoker's paradox in this population [21].

The Optimal Trial In Myocardial Infarction with the Angiotensin Antagonist Losartan (OPTIMAAL) study included selected patients with AMI and evidence of heart failure for randomised treatment with captopril vs. losartan [20]. The unadjusted mortality rate among current smokers was $17 \%$ lower than among non-smokers, but this decreased risk was eliminated after adjustment for age and other baseline differences.

\section{Single centre observational studies of patients with AMI}

Mølstad included 484 unselected AMI patients between 1982 and 1984 [25]. The three-month mortality rate among current smokers was only one-third of that among ex- and never-smokers combined. In a "final" multivariate model, current smoking had a significant protective effect.

Bettencourt et al. [14] and Gaspar et al. [16] included consecutive patients with ACS and could not verify the existence of the smoker's paradox. In the latter study the adjusted analysis indicated a higher six-month mortality rate among current and former vs. never-smokers (Figure 1).

In our own study of 381 unselected NSTEMI patients, smokers in the conservative treatment cohort had significantly higher adjusted one-year mortality than nonsmokers (including ex-smokers) [7]. Such an increased mortality for smokers was not observed in the invasive cohort (data not published).

\section{Registries}

A nationwide prospective survey comprised of patients admitted with AMI in all coronary care units (CCU) operating in Israel during a two-month period [17]. Although the six-month mortality rate among smokers was approximately one-third of that among ex- and never-smokers combined, the adjusted analysis could not verify the smoker's paradox.

Within the Hellenic registry of patients admitted to hospital with AMI [11] there was also no evidence of any adjusted in-hospital survival benefit among current vs. non-smokers.

By far the largest registry in this overview was the National Registry of Myocardial Infarction 2 (NRMI 2) [18], with data from 297,458 patients with confirmed AMI admitted to participating hospitals but without hospital transfer. Crude in-hospital mortality among smokers was $50 \%$ lower than among the on-average 14 years older non-smokers. A highly significant OR for 
reduced mortality in the adjusted analysis supported the existence of a "smoker's paradox".

The Análisis del Retraso en el Infarcto Agudo de Miocardio (ARIAM) registry from Spain included patients with AMI and UAP admitted to a CCU/Intensive Care Unit (ICU) [26]. In patients with AMI, the CCU/ICU mortality was nearly one-third among smokers when compared with non-smokers. The adjusted OR for smokers was significantly in favour of the paradox. The Investigación, Búsqueda Específica y Registro de Isquemia Cooronaria Aguda (IBERICA) registry included patients between 25 and 74 years of age admitted to hospital with AMI. Within this registry, smokers had a lower adjusted 28-day mortality rate than the non-smokers used as evidence in favour of the paradox.

The Global Registry of Acute Coronary Events (GRACE) included patients admitted to hospital with a diagnosis of ACS. In an analysis of 19,325 patients the in-hospital mortality rate among smokers was only half of that among never-smokers (3.3\% vs. 6.9\%). There was no significant difference in adjusted OR for current smokers compared with never-smokers. These results were consistent in all three subgroups of the ACS population studied (STEMI, NSTEMI and unstable angina pectoris).

\section{Confounding factors included in the adjusted analyses}

The confounding variables used in the multivariate analyses (in addition to smoking status) are presented in Table 2. The studies include a wide range of covariates both for baseline risk factors and treatment provided. Four observational studies did not adjust for any treatment provided during hospitalisation $[14,16,25,26]$. Three registries $[15,17,19]$, in addition to the CADILLAC trial [27], included invasive treatment in the multivariate analyses. The NRMI 2 registry adjusted for "any reperfusion therapy" without specifying the proportion of patients undergoing invasive procedures [18]. Only two studies included renal function in the multivariate analyses [24,25].

\section{Comments}

\section{Main findings}

The smoker's paradox was observed in 6 of the 17 studies included as the basis of this review. One of these studies was an observational single-centre study enrolling unselected AMI patients between 1982 and 1984 [25]. The five other studies dated from the late 1980s and early 1990s and included patients according to the former WHO classification and before the routine use of invasive revascularisation $[12,13,15,18,26]$.

\section{Possible explanations of the smoker's paradox}

The possible explanations for the reported paradoxical findings can be categorised as being either due to systematic errors, residual confounding or different pathogenesis: the latter, therefore, representing a true effect of smoking. Systematic errors would include publication bias. The declining frequency of papers reporting the "smoker's paradox" during the last decade supports our argument that the paradox was the result of skewed reports during the 1980s to 1990s. Another systematic error might be that smokers with an acute cardiac event could have a greater case fatality before admission to hospital than non-smokers [15,30,31]. Those admitted alive to the hospital would, therefore, already represent the survivors. This notion is supported by the fact that the smoker's paradox has only been demonstrated in hospitalised patients.

Adjustment for age and co-morbidity did reduce the magnitude of the smoking effect in many of the studies, but not all. Part of the remaining effect could be due to residual confounding, both because of measurement errors in the co-factors and lack of information about relevant risk factors. The six studies supporting a smoker's paradox have included STEMI patients, with fibrinolysis the dominant reperfusion strategy. This may indicate that there are slight differences in the pathogenesis of the acute coronary event in smokers as compared to non-smokers. It has previously been shown that smokers with STEMI have improved myocardial perfusion after fibrinolysis compared to non-smokers, despite adjustment for differences in age and co-morbidities [32,33]. Tobacco smoking is also associated with increased levels of circulating fibrinogen and tissue factor. This suggests a more fibrin-rich thrombus in smokers with STEMI which would leave them more amenable to fibrinolytic therapy [34] and thus an improved survival rate. All these explanations may operate in unison to contribute to the observation that smokers perform better than non-smoker after an AMI.

\section{Studies favouring the paradox Randomised trials}

The International Tissue Plasminogen Activator/Streptokinase Mortality Trial [12] and GISSI-2 [23] had a similar design and enrolled STEMI patients within the same time period.

A "smoker's paradox" was observed in the International study, whereas only a non-significant trend for better outcome for smokers was demonstrated in GISSI2. These two studies bring forward the problem of the classification of former smokers. In the International study the OR for six-month mortality was presented for never-smokers vs. current + former smokers, whilst the contrasting GISSI-2 only reported in-hospital mortality in current vs. never-smokers.

In the GUSTO-1 study, 40,599 patients were included in an analysis of 30-day mortality in relation to smoking 
Table 2 Covariates in addition to smoking status used in the multivariate analyses

\begin{tabular}{|c|c|c|}
\hline Study & Baseline and clinical characteristics & Reperfusion and medication \\
\hline \multicolumn{3}{|c|}{ Studies supporting the existence of a smoker's paradox } \\
\hline Mølstad [25] & Age, atrial fibrillation, s-creatinine, s-potassium & None \\
\hline $\begin{array}{l}\text { Barbash et al. } \\
\text { [12] }\end{array}$ & $\begin{array}{l}\text { Age, sex, MI site, diabetes, previous MI, antecedent angina, } \\
\text { hypertension, hypotension at entry, Killip class, body mass index, } \\
\text { hypercholesterolemia, family history of CAD }\end{array}$ & Time to lysis \\
\hline GUSTO-1 [13] & $\begin{array}{l}\text { Age, sex, systolic blood pressure, Killip class, heart rate, MI site, } \\
\text { previous MI, previous CABG, height, diabetes, hypertension, } \\
\text { cerebrovascular disease }\end{array}$ & Time to lysis, type of thrombolytic treatment \\
\hline NRMI 2 [18] & $\begin{array}{l}\text { Age, sex, MI site, previous MI, previous CABG, weight, diabetes, } \\
\text { hypertension, hypercholesterolemia, family history of CAD, black } \\
\text { race, other race, previous heart failure, previous PTCA, previous } \\
\text { stroke, Q vs. non-Q, }\end{array}$ & $\begin{array}{l}\text { Any reperfusion therapy, aspirin first } 24 \text { hours, any heparin, } \\
\text { intravenous nitroglycerine, beta-blocker, i.v. lidocaine, i.v. } \\
\text { magnesium, ACE-inhibitor, calcium channel blocker, other anti- } \\
\text { thrombin, other antiplatelet }\end{array}$ \\
\hline ARIAM [26] & $\begin{array}{l}\text { Age, Killip class, MI site, diabetes, Q-wave, non-Q-wave with ST } \\
\text { elevation, non-Q-wave with ST decent }\end{array}$ & None \\
\hline IBERICA [15] & $\begin{array}{l}\text { Age, sex, Ml site, previous Ml, diabetes, hypertension, previous } \\
\text { angina, spline function for symptoms monitoring, cardiogenic } \\
\text { shock or acute pulmonary oedema, severe arrhythmias }\end{array}$ & Thrombolysis, primary angioplasty, aspirin, beta-blocker \\
\hline \multicolumn{3}{|c|}{ Studies not supporting the existence of a smoker's paradox } \\
\hline $\begin{array}{l}\text { Gottlieb et al. } \\
\text { [17] }\end{array}$ & $\begin{array}{l}\text { Age, sex, systolic blood pressure }<100 \mathrm{mmHg} \text {, heart rate }>100 / \\
\text { min, Killip class } \geq 2 \text {, anterior } \mathrm{Ml} \text {, diabetes, hypertension, previous } \\
\mathrm{Ml} \text {, previous angina, Q-wave Ml, family history of CAD, CHF } \\
\text { during index hospitalization, atrial fibrillation during } \\
\text { hospitalization }\end{array}$ & Thrombolytic therapy, invasive coronary procedures \\
\hline GISSI-2 [23] & $\begin{array}{l}\text { Age, sex, Killip class, MI site, hypertension, diabetes, previous } \\
\text { angina, body mass index, number of leads with ST elevation }\end{array}$ & Time to lysis \\
\hline TRACE [21] & $\begin{array}{l}\text { Age, sex, body mass index, COPD, previous angina, previous } \mathrm{Ml} \text {, } \\
\text { hypertension, family history of CAD, CHF, wall motion index, } \mathrm{Q} \\
\text { wave anterior Ml }\end{array}$ & Thrombolytic treatment \\
\hline $\begin{array}{l}\text { Andrikopoulos } \\
\text { et al. [11] }\end{array}$ & Age, sex, diabetes, hypertension, previous Ml & Thrombolytic treatment \\
\hline OPTIMAAL [20] & $\begin{array}{l}\text { Age, sex, COPD, cerebrovascular accidents, diabetes, } \\
\text { hypercholesterolemia, hypertension, previous MI, Killip Class, Q } \\
\text { wave MI, Ml site, peripheral vascular disease }\end{array}$ & Thrombolytic treatment, discharge medication \\
\hline $\begin{array}{l}\text { Bettencourt et } \\
\text { al. [14] }\end{array}$ & Age, sex & None \\
\hline GRACE [19] & $\begin{array}{l}\text { Age, sex, geographical region, previous angina, previous MI, } \\
\text { previous PCI/CABG, hypertension, diabetes, hyperlipidemia, } \\
\text { chronic heart failure, Killip class, blood pressure, heart rate }\end{array}$ & $\begin{array}{l}\text { Thrombolytic treatment, catheterization, PCI, CABG, aspirin, UFH, } \\
\text { LMWH, Glycoprotein Ilb/llla inhibitor, ACE-inhibitor, calcium } \\
\text { channel blocker, beta-blocker, statin }\end{array}$ \\
\hline CADILLAC [27] & $\begin{array}{l}\text { Age, sex, Killip class } \geq 2 \text {, Ml site, previous Ml, previous CABG, } \\
\text { diabetes, hypertension, hypercholesterolemia, LAD culprit vessel, } \\
\text { triple vessel disease, baseline TIMI } 0 \text { or } 3\end{array}$ & $\begin{array}{l}\text { Stent randomization, abciximab randomization, time from MI to } \\
\text { ER, time from ER to first balloon }\end{array}$ \\
\hline SYNERGY [24] & $\begin{array}{l}\text { Age, gender, creatinine clearance, heart rate, history of CHF, } \\
\text { diabetes, baseline rales, ST depression on baseline ECG, weight, } \\
\text { peripheral vascular disease, Killip class } 3 \text { or } 4 \text {, No positive } \\
\text { biomarkers at randomization, T-wave inversion on baseline ECG }\end{array}$ & Enoxaparin vs. UFH \\
\hline $\begin{array}{l}\text { Gaspar et al. } \\
{[16]}\end{array}$ & Age, left ventricular dysfunction, Killip class > 1, ST-elevation ACS & None \\
\hline Aune et al. [7] & $\begin{array}{l}\text { Age, s-creatinine, previous left ventricular systolic dysfunction, } \\
\text { interaction term (current smoking/strategy) }\end{array}$ & Invasive strategy, aspirin, statin \\
\hline
\end{tabular}

ACE-inhibitor, angiotensin converting enzyme inhibitor; $C A B G$, coronary artery bypass grafting; CAD, coronary artery disease; CHF, congestive heart failure; COPD, chronic obstructive pulmonary disease; ER, emergency room; LAD, left anterior descending artery; LMWH, low molecular weight heparin; MI, myocardial infarction; $\mathrm{PCl}$, percutaneous coronary intervention; PTCA, percutaneous transluminal coronary angioplasty; UFH, unfractionated heparin.

status. To the best of our knowledge it is in this study that concept of the smokers paradox is first coined. Although not stated expressively in the abstract of the original article, the results from the adjusted analysis were significantly in favour of the paradox in the overall population studied. The abstract refers to the adjusted
OR among 2,431 patients subjected to the angiographic substudy, among which the paradox was not apparent.

\section{Registries}

NRMI 2 reports on 297,458 patients (58\%) without hospital transfer out of 510,044 included patients from 1994 to 1997 [18]. The findings are clearly in favour of 
the paradox. In this report $24 \%$ were current smokers compared with 27 to $28 \%$ in the overall NRMI 2 population [35]. This indicates that the smokers were more likely to be transferred to other hospitals and hence excluded from the analysis. The rather surprising "paradoxical" protective effects of a family history of CAD, hypercholesterolemia and various medical treatments observed in that model were not commented upon by the authors.

The authors of ARIAM point out that registries in general may have inherent defects due to the possibility of unidentified confounders not included in the analyses [26]. A selection bias may have been present since only patients admitted to the participating hospitals ICU/ CCU were included. The IBERICA registry is the only registry supporting the presence of the paradox that incorporated primary PCI in the multivariate regression model. In spite of that, only a minority of patients were subject to such treatment.

The treatment scenario in the late 1980s and early 1990 s was quite different from today's practice. Although the preferred treatment for STEMI now is primary PCI, fibrinolysis remains an important alternative to mechanical revascularisation. In Europe, 5 to $85 \%$ of patients with STEMI undergo primary PCI [36]. Transfer delays may be unacceptably long before primary PCI is performed, especially for patients living in rural areas or reporting to non-PCI centres. As opposed to the thrombolytic era where the paradox was observed, patients who have had successful thrombolysis should be referred within 24 hours for angiography and revascularization as required [37]. In none of the studies and registries supporting the smoker's paradox was such a treatment strategy applied.

\section{The single centre study}

The strength of Mølstad's study is the inclusion of consecutive, unselected patients [25]. At that time no reperfusion modalities were available, and the results are purely of historic interest. This study demonstrates the problems related to multivariate analyses of a small patient population, with results being reliant upon the nature and number of the covariates put into the model. When usage of diuretics was added as a fifth covariate in the multivariate model, there was no longer a significant survival benefit for smokers.

\section{Studies not supporting the paradox Randomised trials}

In TRACE some different confounders to those used in the thrombolytic studies were included, with the study recruiting screenees for a randomised trial [21]. The study population that was screened for entry into TRACE is probably representative of unselected AMI patients admitted to hospital alive with an AMI. On the other hand, OPTIMAAL included highly selected patients with AMI and heart failure [20]. The percentage of patients given fibrinolysis was $54 \%$ in OPTIMAAL screenees and 39\% in TRACE screenees, as opposed to $100 \%$ in the fibrinolytic trials. Such differences, along with selection criteria, may explain the different conclusions reached by these studies and the fibrinolytic studies.

In the more recent CADILLAC trial, in which patients were selected to undergo primary PCI for STEMI, the paradox could not be verified [27]. This suggests that the possible existence of a smoker's paradox does not extend into the invasive era.

In SYNERGY, the only randomised trial including NSTE-ACS with patients scheduled for invasive management, a significantly increased adjusted HR for one-year mortality in current vs. never-smokers was found [24].

\section{Registries}

Both the Israeli [17] and Hellenic [11] registries included hospitalised patients with AMI in the fibrinolytic era. Similar to NRMI 2 [18], IBERICA [15] and ARIAM [26], the mortality rate was compared among current vs. non-smokers, with the results contradictory. It is possible that the number of patients was too small to register the differences noted in the three larger registries.

The GRACE registry was the only study to include patients based upon the current definition of ACS and included in-hospital invasive procedures as a covariate [19]. Neither in the total population of nearly 20,000 patients, nor in the subgroups of patients with STEMI, NSTEMI or UAP, could the existence of the paradox be verified.

\section{Single centre studies}

In neither of the two single centre studies from Portugal $[14,16]$ could the paradox be demonstrated, with one showing a non-significant increase in odds ratio for current vs. non-smokers for six-month mortality [16] (in keeping with the findings from SYNERGY). In our study of NSTEMI patients a significant interaction between treatment strategy (conservative vs. invasive) and smoking at admission was observed implying a statistically significant effect of smoking on mortality. However, due to the statistically significant interaction term between cohort and smoking, the effect of smoking differed between cohorts. Smokers in the conservative cohort had a statistically significant higher adjusted mortality than non-smokers. In this study smokers received a particular clinical benefit from an early invasive strategy [7], and there was no statistically significant differences between mortality for smokers as compared to nonsmokers in the invasive cohort (data not published). Accordingly, there was no evidence for the existence of a smoker's paradox in our study. 


\section{Limitations of the overview}

In a systematic search there will always be a conflict between completeness and accuracy. We tried to perform as wide a search as possible and tested the initial search for possible omissions according to known important publications. Nevertheless, we cannot exclude the possibility of having omitted relevant important studies. In that context, two recent studies that did not meet our inclusion criteria are of interest. They address the important smoking interaction of clopidogrel. Desai et al. presented data from 3,427 STEMI patients [38]. They found that the beneficial effect of clopidogrel was especially pronounced among those who smoked $\geq 10$ cigarettes per day. The other study by Bliden et al. of 259 patients undergoing elective stenting shows that clopidogrel induced increased platelet inhibition and lower aggregation as compared with non-smokers [39]. The design of these studies, however, did not allow for the exploration of the existence of the "paradox".

Due to expected variations in the definition of nonfatal cardiovascular events, as well as the sub-classification of fatal events from 1963 onwards, this overview does not explore possible associations between smoking status and events other than total mortality. In addition, the overview does not include any mechanistic studies. Because of the heterogeneity of the data we did not find it meaningful to make a formal meta-analysis.

\section{Conclusions}

The "smoker's paradox" was predominantly observed in AMI patients selected according to the WHO criteria of the 1980s and 1990s. During that time period fibrinolysis was the dominant reperfusion strategy for such patients. The paradox, however, has not been demonstrated in more recent studies using routine early invasive management, although, in one recent study smokers with NSTEMI have been shown to benefit more from an early invasive strategy than non-smokers. As such, we would be wise to encourage smoking cessation rather than relying on the "positive effects" of the so-called paradox.

\section{Additional material}

Additional file 1: Full search strategy in EMBASE, MEDLINE and Cochrane Central Register of Controlled Trials.

\footnotetext{
Abbreviations

ACE-I: angiotensin converting enzyme inhibitor; ACS: acute coronary syndrome; AMI: acute myocardial infarction; CABG: coronary artery bypass grafting; CAD: coronary artery disease; CCU: coronary care unit; CHF: congestive heart failure; COPD: chronic obstructive pulmonary disease; ER: emergency room; GRACE: global registry of acute coronary events; HR: hazard ratio; ICU: intensive care unit; LAD: left anterior descending artery;
}

LMWH: low molecular weight heparin; MI: myocardial infarction; NSTE-ACS: non-ST-segment elevation acute coronary syndrome; NSTEMI: non-STsegment elevation myocardial infarction; OR: odds ratio; PCl: percutaneous coronary intervention; PTCA: percutaneous transluminal coronary angioplasty; RCT: randomised controlled trial; RR: relative risk; STEMI: STsegment elevation myocardial infarction; UAP: unstable angina pectoris; UFH: unfractionated heparin; WHO: world health organization.

\section{Acknowledgements and Funding}

Thanks to Matthew McGee for proofreading the manuscript. This work was supported by research grants from South-East Norway Regional Health Authority and Vestfold Hospital Trust, Norway.

\section{Author details}

${ }^{1}$ Department of Cardiology, Vestfold Hospital Trust, Tønsberg, Norway. ${ }^{2}$ Department of Biostatistics, Institute of Basic Medical Sciences, University of Oslo, Oslo, Norway. ${ }^{3}$ Morbid Obesity Centre, Vestfold Hospital Trust, Tønsberg, Norway. ${ }^{4}$ Medical Library, Vestfold Hospital Trust, Tønsberg, Norway.

\section{Authors' contributions}

This study was conceived and designed by EA, MM and JEO. The literature search was performed by MM. EA and JEO independently reviewed all titles and abstracts to identify potentially relevant articles. EA, JR, DST and JEO analysed and interpreted the data. EA, DST and JEO drafted the original version of the manuscript. EA, JR, MM, DST and JEO revised the manuscript for critically important intellectual content. All authors have read and approved the final manuscript.

\section{Competing interests}

The authors declare that they have no competing interests.

Received: 21 February 2011 Accepted: 23 August 2011

Published: 23 August 2011

\section{References}

1. Helmers C: Short and long-term prognostic indices in acute myocardial infarction. A study of 606 patients initially treated in a coronary care unit. Acta Med Scand Supp/ 1973, 555:7-26.

2. Kelly TL, Gilpin E, Ahnve S, Henning H, Ross J Jr: Smoking status at the time of acute myocardial infarction and subsequent prognosis. Am Heart J 1985, 110:535-541.

3. Sparrow D, Dawber TR: The influence of cigarette smoking on prognosis after a first myocardial infarction. A report from the Framingham study. J Chronic Dis 1978, 31:425-432.

4. Weinblatt E, Shapiro S, Frank CW, Sager RV: Prognosis of men after first myocardial infarction: mortality and first recurrence in relation to selected parameters. Am J Public Health Nations Health 1968, 58:1329-1347.

5. Libby P, Bonow RO, Mann DL, Zipes DP: Braunwald's Heart Disease: A Textbook of Cardiovascular Medicine Philadelphia: Elsevier Health Sciences; 2007.

6. Aune E, Endresen K, Fox KA, Steen-Hansen JE, Roislien J, Hjelmesaeth J, Otterstad JE: Effect of implementing routine early invasive strategy on one-year mortality in patients with acute myocardial infarction. Am J Cardiol 2010, 105:36-42.

7. Aune E, Endresen K, Roislien J, Hjelmesaeth J, Otterstad JE: The effect of tobacco smoking and treatment strategy on the one-year mortality of patients with acute non-ST-segment elevation myocardial infarction. BMC Cardiovasc Disord 2010, 10:59.

8. Nomenclature and criteria for diagnosis of ischemic heart disease. Report of the Joint International Society and Federation of Cardiology/ World Health Organization task force on standardization of clinical nomenclature. Circulation 1979, 59:607-609.

9. Myocardial infarction redefined-a consensus document of The Joint European Society of Cardiology/American College of Cardiology Committee for the redefinition of myocardial infarction. Eur Heart $J$ 2000, 21:1502-1513.

10. Thygesen K, Alpert JS, White HD: Universal definition of myocardial infarction. Eur Heart J 2007, 28:2525-2538.

11. Andrikopoulos GK, Richter DJ, Dilaveris PE, Pipilis A, Zaharoulis A, Gialafos JE, Toutouzas PK, Chimonas ET: In-hospital mortality of habitual cigarette 
smokers after acute myocardial infarction; the "smoker's paradox" in a countrywide study. Eur Heart J 2001, 22:776-784.

12. Barbash Gl, White HD, Modan M, Diaz R, Hampton JR, Heikkila J, Kristinsson A, Moulopoulos S, Paolasso EA, Van der Werf T, et al: Significance of smoking in patients receiving thrombolytic therapy for acute myocardial infarction. Experience gleaned from the International Tissue Plasminogen Activator/Streptokinase Mortality Trial. Circulation 1993, 87:53-58.

13. Barbash Gl, Reiner J, White HD, Wilcox RG, Armstrong PW, Sadowski Z Morris D, Aylward P, Woodlief LH, Topol EJ: Evaluation of paradoxic beneficial effects of smoking in patients receiving thrombolytic therapy for acute myocardial infarction: mechanism of the "smoker's paradox" from the GUSTO-I trial, with angiographic insights. Global Utilization of Streptokinase and Tissue-Plasminogen Activator for Occluded Coronary Arteries. J Am Coll Cardiol 1995, 26:1222-1229.

14. Bettencourt N, Mateus P, Dias C, Santos L, Adao L, Goncalves C, Simoes L, Gama V: The smoker's-a hemodynamic reality? Rev Port Cardiol 2004, 23:547-555.

15. Elosua R, Vega G, Rohlfs I, Aldasoro E, Navarro C, Cabades A, Demissie S, Segura A, Fiol M, Moreno-Iribas C, Echanove I, Tormo MJ, Arteagoitia JM, Sala J, Marrugat J, IBERICA investigators: Smoking and myocardial infarction case-fatality: hospital and population approach. Eur $J$ Cardiovasc Prev Rehabil 2007, 14:561-567.

16. Gaspar A, Nabalis S, Rocha S, Torres M, Pinto J, Azevedo P, Brandao A Pereira MA, Correia A: Smoking in acute coronary syndromes-the "smoker's paradox" revisited. Rev Port Cardiol 2009, 28:425-437.

17. Gottlieb S, Boyko V, Zahger D, Balkin J, Hod H, Pelled B, Stern S, Behar S: Smoking and prognosis after acute myocardial infarction in the thrombolytic era (Israeli Thrombolytic National Survey). J Am Coll Cardiol 1996, 28:1506-1513.

18. Gourlay SG, Rundle AC, Barron HV: Smoking and mortality following acute myocardial infarction: results from the National Registry of Myocardial Infarction 2 (NRMI 2). Nicotine Tob Res 2002, 4:101-107.

19. Himbert D, Klutman M, Steg G, White K, Gulba DC: Cigarette smoking and acute coronary syndromes: a multinational observational study. Int $J$ Cardiol 2005, 100:109-117.

20. Jaatun HJ, Sutradhar SC, Dickstein K: Comparison of mortality rates after acute myocardial infarction in smokers versus nonsmokers. Am J Cardiol 2004, 94:632-636, A9.

21. Jorgensen, Kober L, Ottesen MM, Torp-Pedersen C, Videbaek J, Kjoller E: The prognostic importance of smoking status at the time of acute myocardial infarction in 6676 patients. TRACE Study Group. J Cardiovasc Risk 1999, 6:23-27.

22. Leung S, Gallup D, Mahaffey KW, Cohen M, Antman EM, Goodman SG, Harrington RA, Langer A, Aylward P, Ferguson JJ, Califf RM, SYNERGY Trial Investigators: Smoking status and antithrombin therapy in patients with non-ST-segment elevation acute coronary syndrome. Am Heart J 2008, 156:177-184.

23. Maggioni AP, Piantadosi F, Tognoni G, Santoro E, Franzosi MG: Smoking is not a protective factor for patients with acute myocardial infarction: the viewpoint of the GISSI-2 Study. G Ital Cardiol 1998, 28:970-978.

24. Mahaffey KW, Yang Q, Pieper KS, Antman EM, White HD, Goodman SG, Cohen M, Kleiman NS, Langer A, Aylward PE, Col J, Reist C, Ferguson J J, Califf RM, SYNERGY Trial Investigators: Prediction of one-year survival in high-risk patients with acute coronary syndromes: results from the SYNERGY trial. J Gen Intern Med 2008, 23:310-316.

25. Molstad P: First myocardial infarction in smokers. Eur Heart J 1991 12:753-759.

26. Ruiz-Bailen M, de Hoyos EA, Reina-Toral A, Torres-Ruiz JM, Alvarez-Bueno M, Gomez Jimenez FJ: Paradoxical effect of smoking in the Spanish population with acute myocardial infarction or unstable angina: results of the ARIAM Register. Chest 2004, 125:831-840

27. Weisz G, Cox DA, Garcia E, Tcheng JE, Griffin JJ, Guagliumi G, Stuckey TD, Rutherford BD, Mehran R, Aymong E, Lansky A, Grines CL, Stone GW: Impact of smoking status on outcomes of primary coronary intervention for acute myocardial infarction-the smoker's paradox revisited. Am Heart J 2005, 150:358-364.

28. Ferguson JJ, Califf RM, Antman EM, Cohen M, Grines CL, Goodman S, Kereiakes DJ, Langer A, Mahaffey KW, Nessel CC, Armstrong PW, Avezum A, Aylward P, Becker RC, Biasucci L, Borzak S, Col J, Frey MJ, Fry E, Gulba DC, Guneri S, Gurfinkel E, Harrington R, Hochman JS, Kleiman NS, Leon MB,
Lopez-Sendon JL, Pepine CJ, Ruzyllo W, Steinhubl SR, et al: Enoxaparin vs unfractionated heparin in high-risk patients with non-ST-segment elevation acute coronary syndromes managed with an intended early invasive strategy: primary results of the SYNERGY randomized trial. JAMA 2004, 292:45-54

29. Kober L, Torp-Pedersen C, Carlsen JE, Bagger H, Eliasen P, Lyngborg K, Videbaek J, Cole DS, Auclert L, Pauly NC: A clinical trial of the angiotensinconverting-enzyme inhibitor trandolapril in patients with left ventricular dysfunction after myocardial infarction. Trandolapril Cardiac Evaluation (TRACE) Study Group. N Engl J Med 1995, 333:1670-1676.

30. McElduff $P$, Dobson AJ: Case fatality after an acute cardiac event: the effect of smoking and alcohol consumption. J Clin Epidemiol 2001 54:58-67.

31. Sonke GS, Stewart AW, Beaglehole R, Jackson R, White HD: Comparison of case fatality in smokers and non-smokers after acute cardiac event. BMJ 1997, 315:992-993.

32. Grines CL, Topol EJ, O'Neill WW, George BS, Kereiakes D, Phillips HR, Leimberger JD, Woodlief LH, Califf RM: Effect of cigarette smoking on outcome after thrombolytic therapy for myocardial infarction. Circulation 1995, 91:298-303.

33. Kirtane AJ, Martinezclark P, Rahman AM, Ray KK, Karmpaliotis D, Murphy SA, Giugliano RP, Cannon CP, Antman EM, Roe MT, Harrington RA, Ohman EM, Braunwald E, Gibson CM: Association of smoking with improved myocardial perfusion and the angiographic characterization of myocardial tissue perfusion after fibrinolytic therapy for ST-segment elevation myocardial infarction. J Am Coll Cardiol 2005, 45:321-323.

34. Sambola A, Osende J, Hathcock J, Degen M, Nemerson Y, Fuster V, Crandall J, Badimon JJ: Role of risk factors in the modulation of tissue factor activity and blood thrombogenicity. Circulation 2003, 107:973-977.

35. Rogers WJ, Canto JG, Lambrew CT, Tiefenbrunn AJ, Kinkaid B, Shoultz DA, Frederick PD, Every N: Temporal trends in the treatment of over 1.5 million patients with myocardial infarction in the US from 1990 through 1999: the National Registry of Myocardial Infarction 1, 2 and 3. J Am Coll Cardiol 2000, 36:2056-2063.

36. Widimsky P, Wijns W, Fajadet J, de Belder M, Knot J, Aaberge L, Andrikopoulos G, Baz JA, Betriu A, Claeys M, Danchin N, Djambazov S, Erne $P$, Hartikainen J, Huber K, Kala P, Klinceva M, Kristensen SD, Ludman P, Ferre JM, Merkely B, Milicic D, Morais J, Noc M, Opolski G, Ostojic M, Radovanovic D, De Servi S, Stenestrand U, Studencan M, et al: Reperfusion therapy for ST elevation acute myocardial infarction in Europe: description of the current situation in 30 countries. Eur Heart J 2010, 31:943-957.

37. Van de Werf F, Bax J, Betriu A, Blomstrom-Lundqvist C, Crea F, Falk V, Filippatos G, Fox K, Huber K, Kastrati A, Rosengren A, Steg PG, Tubaro M, Verheugt F, Weidinger F, Weis M, ESC Committee for Practice Guidelines $(\mathrm{CPG})$ : Management of acute myocardial infarction in patients presenting with persistent ST-segment elevation: the Task Force on the Management of ST-Segment Elevation Acute Myocardial Infarction of the European Society of Cardiology. Eur Heart J 2008, 29:2909-2945.

38. Desai NR, Mega JL, Jiang S, Cannon CP, Sabatine MS: Interaction between cigarette smoking and clinical benefit of clopidogrel. J Am Coll Cardiol 2009, 53:1273-1278.

39. Bliden KP, Dichiara J, Lawal L, Singla A, Antonino MJ, Baker BA, Bailey WL, Tantry US, Gurbel PA: The association of cigarette smoking with enhanced platelet inhibition by clopidogrel. J Am Coll Cardiol 2008, 52:531-533.

\section{Pre-publication history}

The pre-publication history for this paper can be accessed here: http://www.biomedcentral.com/1741-7015/9/97/prepub

doi:10.1186/1741-7015-9-97

Cite this article as: Aune et al.: The "smoker's paradox" in patients with acute coronary syndrome: a systematic review. BMC Medicine 2011 9:97. 